\title{
A new kogiid sperm whale from northern Italy supports psychrospheric conditions in the early Pliocene Mediterranean Sea
}

\author{
Alberto Collareta, Franco Cigala Fulgosi, and Giovanni Bianucci \\ Acta Palaeontologica Polonica 64 (3), 2019: 609-626 doi:https://doi.org/10.4202/app.00578.2018
}

Among living cetaceans, dwarf and pygmy sperm whales (Kogia) are the only members of the family Kogiidae, regarded as diminutive and elusive relatives of the great sperm whale Physeter . Kogiids are known as fossils by several skulls, teeth, and ear bones from Neogene deposits of the Northern Hemisphere and Peru. We report on a fossil kogiid specimen collected at Sant'Andrea Bagni (northern Italy) from Zanclean marine mudstone; these deposits also yielded a rich deep-water elasmobranch assemblage depicting the presence of Atlantic-derived psychrospheric waters. The kogiid specimen, consisting of a partial cranium, one detached tooth, one vertebra, and one fragmentary rib, is here referred to Pliokogia apenninica gen. et sp. nov. Pliokogia is mostly characterised by a long and dorsally flattened rostrum and by the presence of two well-distinct fossae on the right side of the supracranial basin, including an elongated peripheral maxillary fossa on the posterior portion of the right maxilla. Our phylogenetic analysis recovers Pliokogia as a member of the subfamily Kogiinae, which includes Kogia , Koristocetus, Nanokogia, and Praekogia. A low temporal fossa and the absence of dental enamel suggest that, like extant Kogia, Pliokogia was a suction feeder. Since living kogiids do not inhabit the Mediterranean waters, and considering that they feed on deep-water prey in open-sea areas, the association of Pliokogia with a psychrospheric elasmobranch assemblage with Atlantic affinities is noteworthy. Indeed, in early Pliocene times, the Gibraltar connection was controlled by estuarine dynamics, thus allowing the entrance of deep-water organisms (including the putative prey of Pliokogia) in the Mediterranean Basin. The subsequent abandonment of the Mediterranean Sea by kogiids might therefore be related to the definitive establishment of the present-day antiestuarine circulation at Gibraltar, which likely led to a limited deep nutrient supply and resulted in the strong depletion of most Mediterranean deep-water ecosystems.

Key words: Mammalia, Cetacea, Odontoceti, Physeteroidea, Kogiinae, oceanisation, Pliocene, Northern Apennines.

Alberto Collareta [alberto.collareta@unipi.it] and Giovanni Bianucci [giovanni.bianucci@unipi.it ], Dipartimento di Scienze della Terra, Università di Pisa, via Santa Maria 53, 56126, Pisa, Italy. Franco Cigala Fulgosi [cigalaff@libero.it], Strada Martinella 292, 43124 Parma, Italy. 
This is an open-access article distributed under the terms of the Creative Commons

Attribution License (for details please see creativecommons.org), which permits unrestricted use, distribution, and reproduction in any medium, provided the original author and source are credited.

Faris: Full text $(997.7 \mathrm{kB})$ ।

Far Supplementary file $(235.1 \mathrm{kB})$ 